\title{
IGF-I and IGF-binding protein- 1 are related to cortisol in human cord blood
}

\author{
Stefano Cianfarani, Daniela Germani, Laura Rossi ${ }^{1}$, Giovanni Argirò ${ }^{2}$, Sergio Boemi ${ }^{2}$, Marius Lemon $^{3}$, \\ Jeffrey M P Holly ${ }^{4}$ and Francesco Branca ${ }^{1}$ \\ Laboratory of Pediatric Endocrinology, 'Tor Vergata' University, ${ }^{1}$ National Institute of Nutrition and ${ }^{2}$ Division of Nuclear Medicine \\ 'S. Eugenio' Hospital, Rome, Italy and Departments of ${ }^{3}$ Chemical Pathology and ${ }^{4}$ Surgery, Bristol Royal Infirmary, Bristol, UK
}

(Correspondence should be addressed to S Cianfarani, Laboratory of Pediatric Endocrinology, Room E-178 'Tor Vergata' University, via di Tor Vergata 135, 00133-Rome, Italy)

\begin{abstract}
Objective: To assess cortisol concentrations in cord blood and investigate their relationships with the IGF system.

Study design: Fifteen newborns with birth weight appropriate for gestational age (AGA) and 30 children with intrauterine growth retardation (IUGR) were studied. Serum samples were collected from umbilical cord blood and cortisol, IGF-I and IGF-binding proteins (IGFBPs)-1 and -3 were measured. IUGR infants were followed up for 3 months with repeated measurements of weight, supine length and knee-heel length (by knemometry).

Results: IUGR newborns showed significantly greater concentrations of IGFBP-1 $(P<0 \cdot 0001)$ and lower concentrations of IGF-I $(P<0.0001)$ and IGFBP-3 $(P<0.0001)$ than did controls. In AGA children, cortisol correlated inversely with IGF-I $(r=-0.75, P<0.002)$ and directly with IGFBP-1 $(r=0.52, P<0 \cdot 05)$, whereas no correlation between cortisol and IGF system-related variables was observed in IUGR. Finally, in IUGR children an inverse correlation was found between length gain in the first trimester of life and cortisol concentrations at birth $(r=-0.54, P<0.005)$.

Conclusions: Cortisol might be a physiological regulator of fetal growth, at least in the last part of pregnancy, by modulating IGF-I and IGFBP-1 release under conditions of fetal stress. In IUGR children, a rearrangement of this growth control mechanism seems to occur. The close inverse relationship of cortisol with linear growth, if confirmed by large-scale studies, suggests cord blood cortisol to be potentially predictive of early postnatal catch-up growth in IUGR infants.
\end{abstract}

European Journal of Endocrinology 138 524-529

\section{Introduction}

The fetal endocrine system, and particularly the somatotrophic axis, is actively involved in mediating the effects of maternal, placental or fetal status on intrauterine growth. However, the relative importance of growth hormone $(\mathrm{GH})$ and the insulin-like growth factors (IGFs-I and -II) appears to differ in pre- and postnatal life $(1,2)$. Whereas abnormalities of fetal GH secretion are not associated with major alterations in body size at birth $(3,4)$, IGF-I deficiency has been shown to cause marked fetal growth retardation $(5,6)$. IGF-I is therefore a major stimulus for both pre- and postnatal growth, but appears to be regulated by $\mathrm{GH}$ only after birth. IGFs are part of a complex system comprising IGFs-I and -II, types 1 and 2 IGF receptors, six different IGF-binding proteins (IGFBPs-1 to -6), specific IGFBP proteases and inhibitors of IGFBP proteolytic activity (7), and it is likely that, before birth, the delicate balance within this system and its interactions with endocrine, metabolic and nutritional factors have pivotal roles in controlling fetal growth. We have recently reported a reorganization of the somatotrophic axis in newborn infants who had intrauterine growth retardation (IUGR), suggesting that the IGFdependent growth-promoting machinery is 'frozen' at birth and begins to work within the first 60 days of postnatal life $(8,9)$.

In the progressive maturation of the fetal endocrine system during intrauterine life, cortisol is known to contribute to preparing the fetus for birth by inducing the expression of a wide range of enzymes that have little or no function during fetal life, but on which survival after birth is dependent $(4,10)$. During fetal development, there is a progressive increase in plasma concentrations of cortisol in the last 15-20 days of gestation and a dramatic surge in the final few days before birth (11).

The increase in fetal plasma cortisol has recently been proposed to be responsible for the prepartum decline in 
IGF-II gene expression in specific fetal tissues (12), and the expression of GH receptors and IGF-I mRNA in an animal model (13). The aim of this study was to assess cortisol concentrations in cord blood of normal and IUGR newborns and to investigate the relationships of cortisol with the IGF system-related variables.

\section{Subjects and methods}

\section{Subjects}

Thirty IUGR children with birth weight less than the 10th centile for gestational age according to the standards of Lubchenko et al. (14), and 15 children with birth weight appropriate for gestational age (greater than the 25th centile) (AGA) were included in the study. All were born after a full-term, uneventful pregnancy (38-42 weeks). All control children were born by normal vaginal delivery, whereas among IUGR children, 11 were born by vaginal delivery and 19 by caesarean section. Newborns with malformations or genetic disorders were excluded.

IUGR children underwent measurements of weight and supine length at birth, and weight, supine length and knee-heel length at 7, 14, 30, 60 and 90 days of life. Serum samples were collected from the umbilical cord of the babies at birth and stored at $-25^{\circ} \mathrm{C}$ until required for assay. IGF-I, IGFBP-3, IGFBP-1 and cortisol concentrations were measured.

The investigation was approved by the Ethics Committee of the 'Tor Vergata' University Medical School and written informed consent to study their children was obtained from all the parents.

\section{Anthropometry}

Anthropometric measurements were carried out by two observers who were trained over a period of 2 months. Supine length was measured with a portable infantometer (Rollametre, Raven Equipment Ltd, Great Dunmow, Essex, UK).

The Ponderal Index (PI: weight $(\mathrm{g}) /$ length $\left.(\mathrm{cm})^{3}\right)$ was used to discriminate between children with proportionate and non-proportionate intrauterine growth retardation. Children with PI $\geq 10$ th centile of the reference (15) were defined as proportionate and those with PI <10th centile were defined as non-proportionate. Catch-up growth was defined as length and weight increments greater than the 50th centile of the reference values (16).

Knee-heel length was measured with a portable knemometer (Force Institute, Copenhagen, Denmark). The instrument, described by Michaelsen et al. (17), is made of a fixed graduated rod ending with a knee cap and a sliding rod, fitted with a heel cap and connected to a digital caliper that allows measurement with $0.01 \mathrm{~mm}$ resolution. A series of five measurements was taken, with the knemometer removed and repositioned each time. If the S.D. exceeded $0.8 \mathrm{~mm}$, the entire series of five assessments was repeated.

\section{Assays}

IGF-I was determined by RIA after acid-ethanol extraction (Nichols Institute, San Juan Capistrano, CA, USA); the intra-assay coefficient of variation (CV) was $3.0 \%$, the interassay CV $8.4 \%$, and the limit of sensitivity $13.5 \mu \mathrm{g} / \mathrm{l}$. In accordance with the recommendations for valid measurement of total IGF-I concentrations in biological fluids (18), in 33 samples IGF-I was also measured by RIA after acid-acetone extraction (19) and potential residual IGFBP binding sites were blocked by the addition of $10 \mathrm{ng}$ IGF-II to each tube in the IGF-I assay. IGF-I concentrations assessed after acid-ethanol extraction correlated closely with those obtained after acid-acetone extraction and addition of an excess of IGF-II $(r=0.80, P<0.0001)$, being slightly, but not significantly, lower. IGFBP-3 was assessed by RIA (Diagnostic Systems Laboratories Inc., Webster, TX, USA); the intra-assay CV was $6.7 \%$, the interassay CV $10.1 \%$ and the limit of sensitivity $0.2 \mathrm{mg} /$ l. IGFBP-1 was measured by an immunoenzymatic monoclonal assay (IEMA-test, Medix Biochemica, Kauniainen, Finland); the intra-assay CV was $3.4 \%$, the interassay $\mathrm{CV} 7.4 \%$ and the limit of sensitivity $0.4 \mu \mathrm{g} / \mathrm{l}$. Cortisol was measured by RIA (Orion Diagnostica, Espoo, Finland). The intra-assay CV was $4.0 \%$, the interassay $\mathrm{CV} 9.0 \%$ and the limit of sensitivity $0.25 \mu \mathrm{g} / \mathrm{dl}$.

\section{Statistics}

Results are reported as the mean \pm s.E.M. Differences between groups were assessed using the MannWhitney $U$ test. Significance was assigned at $P<0.05$. The relationship between parameters was evaluated using the Pearson correlation. IGFBP-1 values were transformed to natural logs to achieve normal distribution before parametric statistical methods were applied. A computer program was used for all statistical calculations (BMPD Statistical Software, SOLO 3.0).

\section{Results}

Mean birth weight was $3.49 \pm 0.08 \mathrm{~kg}$ in control infants and $2.32 \pm 0.03 \mathrm{~kg}$ in the IUGR group $(P<0.0001)$. The mean PI of the IUGR newborns was $2.29 \pm 0.04$; among this group, 18 were classified as proportionate and 12 as non-proportionate. From 0 to 90 days the IUGR children showed a mean weight gain of $2.79 \pm 0.08 \mathrm{~kg}$, a mean length increase of $10.37 \pm$ $0.32 \mathrm{~cm}$ and a mean knee-heel growth of $32.24 \pm$ $1.39 \mathrm{~mm}$.

IUGR newborns had significantly greater concentrations of IGFBP-1 $(P<0.0001)$ and lower concentrations of IGF-I $(P<0.0001)$ and IGFBP-3 $(P<0.0001)$ than the control group (Table 1). 
Table 1 Endocrine variables at birth (umbilical cord serum) in AGA and IUGR children. Values are expressed as means \pm S.E.M.

\begin{tabular}{|c|c|c|c|c|}
\hline & \multirow{2}{*}{$\begin{array}{l}\text { AGA newborns } \\
\text { Vaginal delivery } \\
\quad(n=15)\end{array}$} & \multicolumn{3}{|c|}{ IUGR newborns } \\
\hline & & $\begin{array}{l}\text { Vaginal delivery } \\
\quad(n=11)\end{array}$ & $\begin{array}{c}\text { Caesarean section } \\
(n=19)\end{array}$ & $\begin{array}{l}\text { Overall } \\
(n=30)\end{array}$ \\
\hline $\begin{array}{l}\text { IGF-I (nmol/l) } \\
\text { IGFBP-3 (nmol/l) } \\
\text { IGFBP-1 }(\mu \mathrm{g} / \mathrm{l}) \\
\text { Cortisol (nmol/l) }\end{array}$ & $\begin{array}{r}7.8 \pm 0.8 \\
41.9 \pm 3.9 \\
39.3 \pm 5.6 \\
441 \pm 47\end{array}$ & $\begin{aligned} 2.5 & \pm 0.5^{\star * *} \\
23.6 & \pm 2.6^{* * *} \\
110.3 & \pm 16.8^{* * *} \\
317 & \pm 36\end{aligned}$ & $\begin{array}{c}2.0 \pm 0.2^{* * *} \\
24.6 \pm 2.9^{\star \star *} \\
124 \pm 12^{\star * \star} \\
215 \pm 33^{\star, * * *}\end{array}$ & $\begin{aligned} 2.3 & \pm 0.2^{* * *} \\
23.9 & \pm 1.9^{* \star *} \\
117.1 & \pm 11.2^{\star \star *} \\
256 & \pm 25^{\star * *}\end{aligned}$ \\
\hline
\end{tabular}

${ }^{* * *} P \leq 0.001$ compared with controls; ${ }^{*} P<0.05$ within IUGR groups.

No significant difference in IGF-I, IGFBP-3 and IGFBP-1 concentrations was observed between IUGR children born by vaginal delivery and those born by caesarean section, whereas cortisol concentrations were significantly lower in children born by caesarean section than in those born by vaginal delivery $(P<0.05)$ and in controls $(P<0.005$; Table 1$)$.

No significant difference in IGF-I, IGFBP-3, IGFBP-1 and cortisol concentrations was seen between proportionate and non-proportionate IUGR newborns.

In AGA newborns, the cortisol concentrations were inversely related to IGF-I $(r=-0.75, P<0.002$; Fig. 1$)$, and directly to IGFBP-1 $(r=0.52, P<0.05$; Fig. 2$)$, and these relationships remained after we had controlled for all anthropometric and endocrine variables. No correlation between cortisol and these two analytes was shown in the IUGR group, and no relationship between cortisol and IGFBP-3 concentrations was observed in either group.

In IUGR children, the gain in both supine and kneeheel length during the first trimester of life was inversely related to cord blood cortisol $(r=-0.54$ and $r=-0.58$ respectively, $P<0.05$; Fig. 3). The correlation between length gain and cortisol concentrations at birth was observed both in IUGR infants born by caesarean section $(r=-0.52, P<0.05)$ and in those born by vaginal delivery $(r=-0.61, P<0.05)$. An inverse relationship between weight gain and cord blood cortisol concentrations was also seen, but just failed to achieve significance $(r=-0.31, P=0.051)$.

Overall, cord blood cortisol concentrations were significantly lower in IUGR children who showed catch-up growth during the first 3 months of life than in those who did not $(8.3 \pm 0.9$ and $13.2 \pm 2.3 \mu \mathrm{g} / \mathrm{dl}$ respectively, $P<0.05)$. No relationship was seen between IGF-I, IGFBP-3 and IGFBP-1 cord blood concentrations and the first trimester catch-up growth in IUGR infants.

\section{Discussion}

Our data confirm the findings of previous studies showing that IUGR newborns have significantly lower

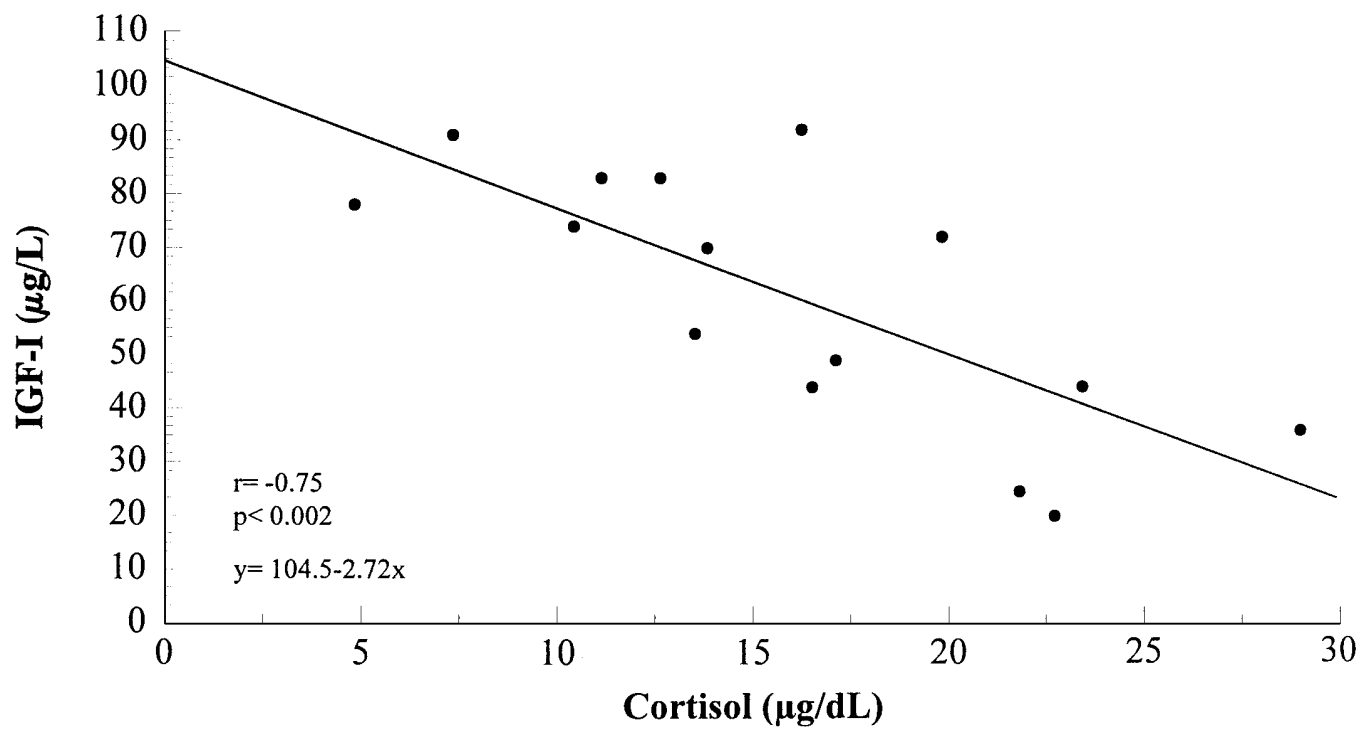

Figure 1 Relationship between cortisol and IGF-I concentrations in serum samples of normal (AGA) newborn infants. Cortisol and IGF-I were determined by specific RIAs in serum obtained from the umbilical cord. 


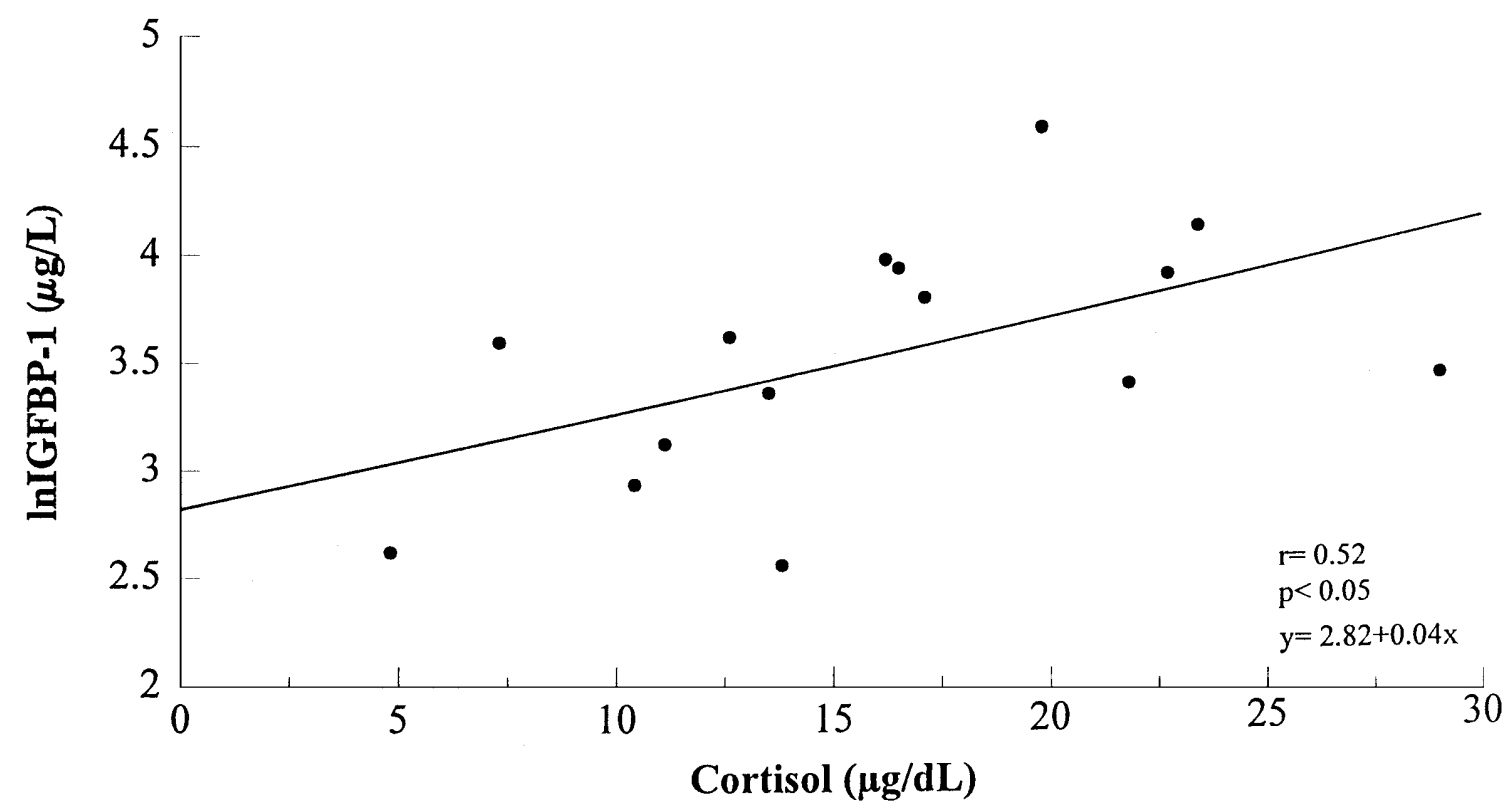

Figure 2 Relationship between cortisol and IGFBP-1 concentrations (expressed as $\log _{e}$ IGFBP-1) in serum samples of normal (AGA) newborn infants. Cortisol was determined by specific RIA and IGFBP-1 by IEMA in serum obtained from umbilical cord.

concentrations of IGF-I and IGFBP-3, and greater concentrations of IGFBP-1 than control infants (2022 ), indicating a reorganization of the IGF system during fetal life. The endocrine profile of cord blood of IUGR infants, characterized by high IGFBP-1 and low IGF-I and IGFBP-3 concentrations, might reflect the necessity to divert the limited fetal energy resource expenditure from body growth in favour of the survival and development of vital organs.
The results of this study first show a close inverse correlation between circulating concentrations of cortisol and IGF-I in normal newborn infants. This finding is consistent with the increasing body of evidence from in vitro data suggesting that cortisol inhibits the transcription of IGF-I in animal and human osteoblasts (23, 24). Conversely, Li et al. (13) have recently reported that the prepartum cortisol surge stimulates the expression of hepatic GH receptor and IGF-I genes in

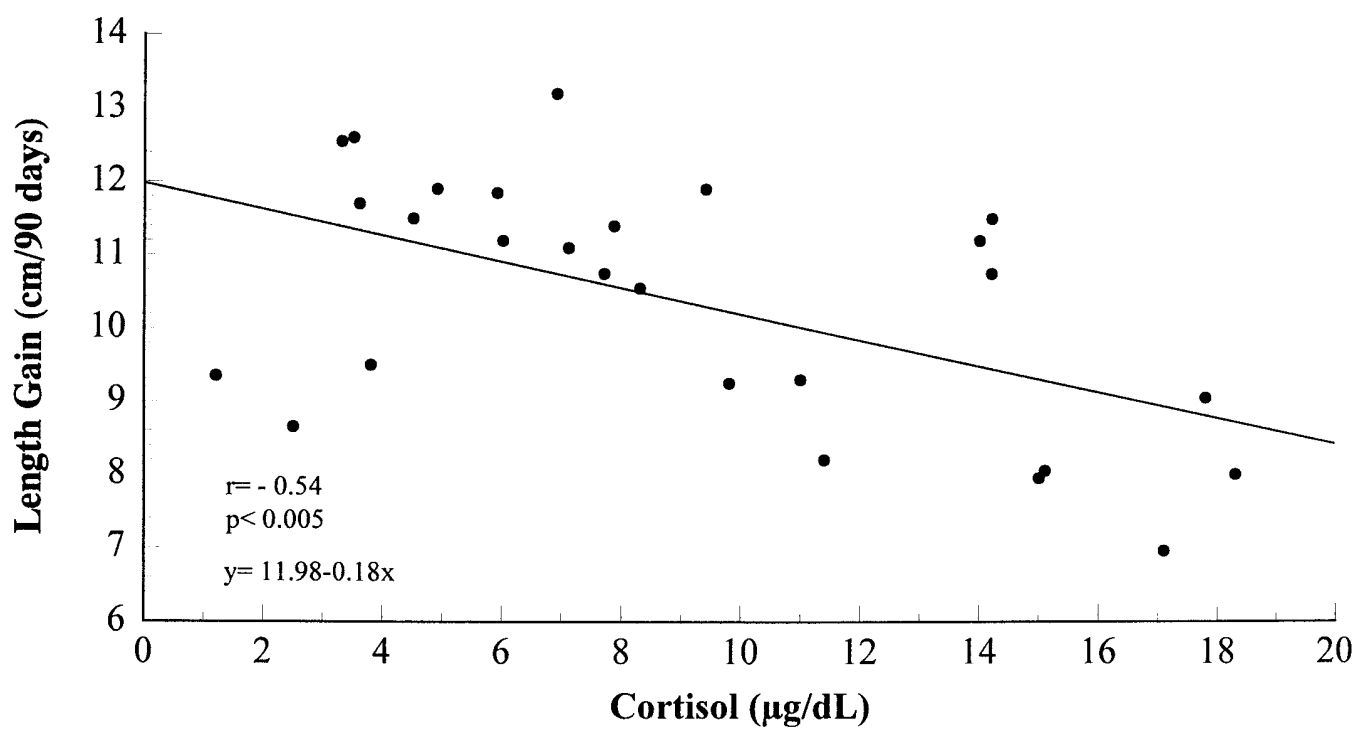

Figure 3 The relationship between cortisol concentrations at birth and the length gain of IUGR infants during the first 90 days of life. Cortisol was measured by specific RIA in serum obtained from umbilical cord. Supine length gain was measured with a portable infantometer. 
fetal sheep, suggesting that the effect of cortisol on the expression of IGF-I in the fetal liver might be either direct or mediated by the upregulation of hepatic $\mathrm{GH}$ receptors, or through an effect on the signalling pathway of the GH receptor. It is noteworthy, however, that Li's group failed to observe any significant cortisolinduced change in the circulating concentrations of IGF-I.

The inverse relationship between circulating concentrations of cortisol and IGF-I in normal newborns, together with the direct relationship between cortisol and IGFBP-1, suggests that, in fetuses, cortisol might exert a control on linear growth through a modulation of IGF-I and IGFBP-1 secretion. It is tempting to speculate that, during conditions of stress, fetal growth might be affected by the increase in cortisol concentrations that directly reduces the release of IGF-I in circulation and indirectly downmodulates IGF-I biological activity by enhancing the expression of IGFBP-1 (25).

Our observation of a close inverse relationship between cord blood cortisol concentrations and the gain in length during the first 3 months of extrauterine life in IUGR infants, if confirmed by large-scale studies, might be of great practical relevance. Most IUGR children who eventually achieve normal size show a rapid growth rate during the first 6 months of life (26), and hormonal or nutritional treatment in the immediate postnatal period might be considered in those who do not present an early catch-up growth (27). Cord blood cortisol concentrations may provide a means of predicting the catch-up growth in IUGR infants, and an early therapeutic intervention, aimed at stimulating growth, might be advisable in those IUGR children with high cortisol concentrations at birth. However, the lack of relationships between cortisol, IGF-I and IGFBP-1 in IUGR newborns leaves the mechanisms underlying the growth-inhibiting actions of cortisol unclear. IUGR fetus shows endocrine features resembling those of malnourished children (8) and nutritional status is a major determinant of IGF-I and IGFBP-1 concentrations. Therefore, in conditions of nutrition-induced suppression of IGF-I and stimulation of IGFBP-1 release into the circulation, such as prevail in IUGR, cortisol might exert its negative control on growth at a cellular level, modulating the local expression of IGF-I and IGFBP-1 genes, as has been demonstrated in bone $(23,24,28$, 29).

Finally, our results confirm the occurrence of significantly greater fetal concentrations of cortisol after normal labour than after caesarean section $(30,31)$, whereas no differences in IGF-I, IGFBP-3 or IGFBP-1 concentrations were found between IUGR children born by vaginal delivery and those born by caesarean section.

In conclusion, our results show, for the first time, an inverse relationship between cord blood cortisol and IGF-I concentrations and a direct correlation between cortisol and IGFBP-1 concentrations in normal newborns, suggesting that cortisol may modulate IGF-I and IGFBP-1 release during fetal life. These endocrine relationships seem to be lost in IUGR children. We have also presented the first report of an inverse relationship between cord blood cortisol concentrations and length gain in the first 3 months of life in IUGR newborns. A study involving a larger group of children for a longer period of time is required to confirm these preliminary results that might suggest cortisol to be a predictive factor of early postnatal catch-up growth.

\section{Acknowledgements}

Dr Stefano Cianfarani was partly supported by NATOCNR Senior Fellowship grant No. 217.28/04.

\section{References}

1 Gluckman PD \& Liggins GC. Regulation of fetal growth. In Fetal Physiology and Medicine, pp 511-588. Eds RW Beard \& PW Nathanielsz. New York: Marcel Dekker, 1984.

2 Chard T. Hormonal control of growth in the human fetus. Journal of Endocrinology 1989123 3-9.

3 Bassett JM, Thorburn GD \& Wallace ACL. The plasma growth hormone concentrations of the fetal lamb. Journal of Endocrinology $197048251-263$.

4 Fowden AL. Endocrine regulation of fetal growth. Reproduction Fertility and Development 19957 351-363.

5 Baker J, Liu J-P, Robertson EJ \& Efstratiadis A. Role of insulin-like growth factors in embryonic and postnatal growth. Cell 199375 $73-82$.

6 Liu J-P, Baker J, Perkins AS, Robertson EJ \& Efstratiadis A. Mice carrying null mutations of the genes encoding insulin-like growth factor-I (Igf-1) and type-1 IGF receptor (Igf1r). Cell 199375 59-72.

7 Giudice LC. Insulin-like growth factors and ovarian follicular development. Endocrine Reviews 199213 641-669.

8 Cianfarani S, Germani D, Rossi L, Germani A, Ossicini C, Zuppa A et al. The growth promoting machinery is jammed in IUGR newborns and is fully restored by two months of life (Abstract). Endocrinology and Metabolism 19964 (Suppl A) 12-011.

9 Cianfarani S, Germani D, Rossi P, Rossi L, Germani A \& Branca F. IGFBP-3 proteolytic activity in children with intrauterine growth retardation. Journal of Endocrinology 1996151 (Suppl) 29 (Abstract).

10 Liggins GC. The role of cortisol in preparing the fetus for birth. Reproduction Fertility and Development 19946 141-150.

11 Brooks AN, Hagan DM \& Howe DC. Neuroendocrine regulation of pituitary-adrenal function during fetal life. European Journal of Endocrinology 1996135 153-165.

12 Li J, Saunders JC, Gilmour RS, Silver M \& Fowden AL. Insulin-like growth factor-II messenger ribonucleic acid expression in fetal tissues of the sheep during late gestation: effects of cortisol. Endocrinology 1993132 2083-2089.

13 Li J, Owens JA, Owens PC, Saunders JC, Fowden AL \& Gilmour RS. The ontogeny of hepatic growth hormone receptor and insulinlike growth factor I gene expression in the sheep fetus during late gestation: developmental regulation by cortisol. Endocrinology $19961371650-1657$.

14 Lubchenco LO, Hansman C, Dressler M \& Boyd R. Intrauterine growth as estimated from liveborn birthweight data at 24 to 42 weeks of gestation. Pediatrics 196332 793-800.

15 Lubchenko LO, Hansman C \& Boyd E. Intrauterine growth in length and head circumference as estimated from live births at gestational ages from 26 to 42 weeks. Pediatrics 196637 403-408.

16 Guo S, Roche AF, Fomon SJ, Nelson SE, Chumlea WC, Rogers RR et al. Reference data on gains in weight and length during the first two years of life. Journal of Pediatrics 1991119 355-362. 
17 Michaelsen KF, Skov L, Badsberg JH \& Jorgensen M. Short-term measurement of linear growth in preterm infants: validation of a hand-held knemometer. Pediatric Research 199130 464-468.

18 Consensus Statement. Valid measurement of total IGF concentrations in biological fluids. Recommendations from the 3rd International Symposium on insulin-like growth factors. Journal of Endocrinology $1994143 \mathrm{C} 1-\mathrm{C} 2$.

19 Holly JMP, Biddlecombe RA, Dunger DB, Edge JA, Amiel SA, Howell R, Chard T, Rees LH \& Wass JAH. Circadian variation of $\mathrm{GH}(\mathrm{mcg} / \mathrm{L})$-independent IGF-binding protein in diabetes mellitus and its relationship to insulin. A new role for insulin? Clinical Endocrinology $198829667-675$.

20 Lassarre C, Hardouin S, Daffos F, Forestier F, Frankenne F \& Binoux M. Serum insulin-like growth factors and insulin-like growth factor binding proteins in the human fetus. Relationships with growth in normal subjects and in subjects with intrauterine growth retardation. Pediatric Research 1991 29 219-225.

21 Giudice LC, de Zegher F, Gargosky SE, Dsupin BA, de las Fuentes L, Crystal RA et al. Insulin-like growth factors and their binding proteins in the term and preterm human fetus and neonate with normal and extremes of intrauterine growth. Journal of Clinical Endocrinology and Metabolism 199580 1548-1555.

22 Hills FA, English J \& Chard T. Circulating levels of IGF-I and IGFbinding protein-1 throughout pregnancy: relation to birthweight and maternal weight. Journal of Endocrinology 1996148 303-309.

23 Delany AM \& Canalis E. Transcriptional repression of insulin-like growth factor-I by glucocorticoids in rat bone cells. Endocrinology $19951364776-4781$.
24 Swolin D, Brantsing C, Matejka G \& Ohlsson C. Cortisol decreases IGF-I messenger-RNA levels in human osteoblast-like cells. Journal of Endocrinology 1996149 397-403.

25 Holly JMP. The physiological role of IGFBP-1. Acta Endocrinologica $199112455-62$

26 Karlberg J \& Albertsson-Wikland K. Growth in full-term small for gestational age infants: from birth to final height. Pediatric Research $199538733-739$.

27 Chernausek SD. The growth hormone/insulin like growth factor axis in intrauterine growth retardation: pathophysiological and therapeutic implications. Endocrinologist 19966 294-300.

28 Conover CA, Divertie GD \& Lee PDK. Cortisol increases plasma insulin-like growth factor binding protein-1 in humans. Acta Endocrinologica 1993128 140-143.

29 Conover CA, Lee PDK, Riggs BL \& Powell DR. Insulin-like growth factor binding-protein-1 expression in cultured human bonecells. Regulation by insulin and glucocorticoids. Endocrinology 1996137 3295-3301.

30 Bagnoli F, Bruchi S, Garosi G, Inaudi P, Massafra C \& Bracci R. Progesterone and cortisol plasma levels at birth. Influence of labor and fetal distress. Rivista Italiana di Pediatria 199117 660-664.

31 Bird JA, Spencer JAD, Mould T \& Symonds ME. Endocrine and metabolic adaptation following caesarean section or vaginal delivery. Archives of Diseases in Childhood 199674 132-134.

Received 20 November 1997

Accepted 5 February 1998 